\title{
Avaliação da qualidade da água do riacho São Caetano, de Balsas (MA), com base em parâmetros físicos, químicos e microbiológicos
}

\author{
Evaluation of the water quality of São Caetano creek, in Balsas-MA, \\ based on physical, chemical and microbiological parameters
}

\author{
Regina Maria Mendes Oliveira', Ezequiel Vieira dos Santos ${ }^{2}$, Kalyl Chaves Lima ${ }^{3}$
}

\begin{abstract}
RESUMO
Este trabalho tem como objetivo avaliar a qualidade da água do riacho São Caetano, de Balsas (MA), com base na resolução CONAMA no 357/2005. Os parâmetros físicos, químicos e microbiológicos foram analisados e o Índice de Qualidade da Água (IQA) foi determinado. Os dados classificam riacho como ambiente impactado, com características eutróficas. No geral, a contaminação da água por coliformes termotolerantes está acima dos padrões estabelecidos para águas de classe 2, e os valores de IQA são indicativos de que a água possui qualidade regular. Também foram observadas ações antrópicas negativas nas margens do riacho, um indicativo de que há necessidade urgente de medidas de preservação.
\end{abstract} Palavras-chave: qualidade da água; IQA; atividades antrópicas.

\begin{abstract}
This study aims to assess the water quality of São Caetano creek, in Balsas (MA), based on the CONAMA Resolution No. 357/2005. The physical, chemical and microbiological parameters were analyzed, and the Water Quality Index (WQI) was determined. The data classify creek as an impacted environment, with eutrophic characteristics. In general, the water contamination by fecal coliform is above the standards set for Class 2 waters, and the WQI values are indicative of regular quality waters. Also, there were observed negative anthropic actions at the margins of the creek, an indication that there is an urgent need for conservation measures.
\end{abstract}

Keywords: water quality; WQI; anthropogenic activities.

\section{INTRODUÇÃO}

A água é um recurso de importância inestimável à sobrevivência humana e, entre seus múltiplos usos, estão o abastecimento público e industrial, a irrigação agrícola, a produção de energia elétrica e as atividades de lazer e recreação. Entretanto, o crescimento populacional e a expansão das atividades industriais podem estar relacionados à origem da poluição em locais que possuem infraestrutura inadequada de esgoto sanitário e falta de gestão de resíduos sólidos.

Acompanhando a tendência global de crescimento populacional, o município de Balsas (Figura 1), localizado no sul do Estado do Maranhão, com área territorial de $13.141,733 \mathrm{~km}^{2}$, passou de 41.640 habitantes, em 1992, para 83.528, em 2010 (IBGE, 2010).

Esse município, com alto potencial no setor do agronegócio, é banhado pelo rio de mesmo nome, que tem cerca de $510 \mathrm{~km}$ de extensão, e dispõe de nove riachos em seu perímetro urbano - todos efluentes do rio Balsas - , sendo um ponto turístico para o lazer. Porém, a escassez de políticas públicas tem agravado os problemas socioambientais nesse município nos últimos anos.

Desde a década de 1980, o riacho São Caetano, um dos afluentes do rio Balsas, tem sofrido degradação com a expansão imobiliária, com o lançamento de efluentes domésticos e com a liberação de compostos químicos diretamente em suas águas pelos lava-jatos automotivos que se encontram ao longo do seu percurso (OLIVEIRA, 2014). Contudo, estudos mostram que parte da população ribeirinha desse riacho faz uso de suas águas em atividades como banho e lavagens de roupas e de veículos (OLIVEIRA, 2014).

Assim, a coleta de informações a respeito da qualidade da água é muito importante para uma definição adequada de tecnologias e de medidas a serem adotadas em seu tratamento. Nesse contexto, o objetivo deste estudo consiste em avaliar os impactos do lançamento de efluentes domésticos na qualidade da água do riacho São Caetano.

'Doutora em Química Inorgânica pela Universidade Federal de São Carlos (UFSCar) - São Carlos (SP), Brasil.

${ }^{2}$ Graduando do Curso de Ciência e Tecnologia da Universidade Federal do Maranhão (UFMA) - Balsas (MA), Brasil.

${ }^{3}$ Graduando do Curso de Ciência e Tecnologia da UFMA - Balsas (MA), Brasil.

Endereço para correspondência: Regina Maria Mendes Oliveira - Rua José Leão, 484 - Centro - 65800-000 - Balsas (MA), Brasil - E-mail: regina.oliveira@ufma.br.

Recebido: 25/09/15 - Aceito: 11/07/16 - Reg. ABES: 154657 


\section{METODOLOGIA}

Inicialmente, foi realizado um monitoramento preliminar do riacho São Caetano no que se refere às modificações antrópicas, em que a principal estratégia de ação foi o registro de imagens e anotações.

As coletas de água foram realizadas nos seguintes pontos: $\mathrm{P} 1$, próximo à nascente do riacho (latitude: $7^{\circ}$ 51' 87.79" S; longitude: $46^{\circ} 04^{\prime} 72.89^{\prime \prime}$ W; endereço: Avenida Contorno, bairro: Potosí); P2, após a Lagoa do Jardel (latitude: $7^{\circ} 52^{\prime}$ 49.84” S; longitude: 46 03' 96.1” W; endereço: Av. Antônio Leitão, bairro: Centro); P3, latitude: $7^{\circ}$ 52' 74.87” S; longitude: $46^{\circ} 03^{\prime}$ 60.34" W; endereço: Av. Coronel Fonseca, bairro: Centro); e $\mathrm{P} 4$, próximo à desembocadura no rio Balsas (latitude: $7^{\circ}$ 52' 71.91" S; $46^{\circ} 02^{\prime}$ 84.38” W; endereço: Rua Isaac Martins, bairro: Manoel Novo). A localização dos pontos é ilustrada na Figura 2.

As amostras de água foram coletadas em frascos de plástico (polietileno), com capacidade de $500 \mathrm{~mL}$, previamente esterilizados. As coletas foram realizadas segundo os procedimentos de coleta de amostras de água contidos no Guia de coleta e preservação de amostras de água da CETESB (2011). Todas as amostras foram acondicionadas ao abrigo de luz solar em uma caixa térmica com gelo, sendo os respectivos vasilhames de coleta identificados com os dados da amostra (número do ponto). Além dos cuidados gerais, também foram registradas as informações

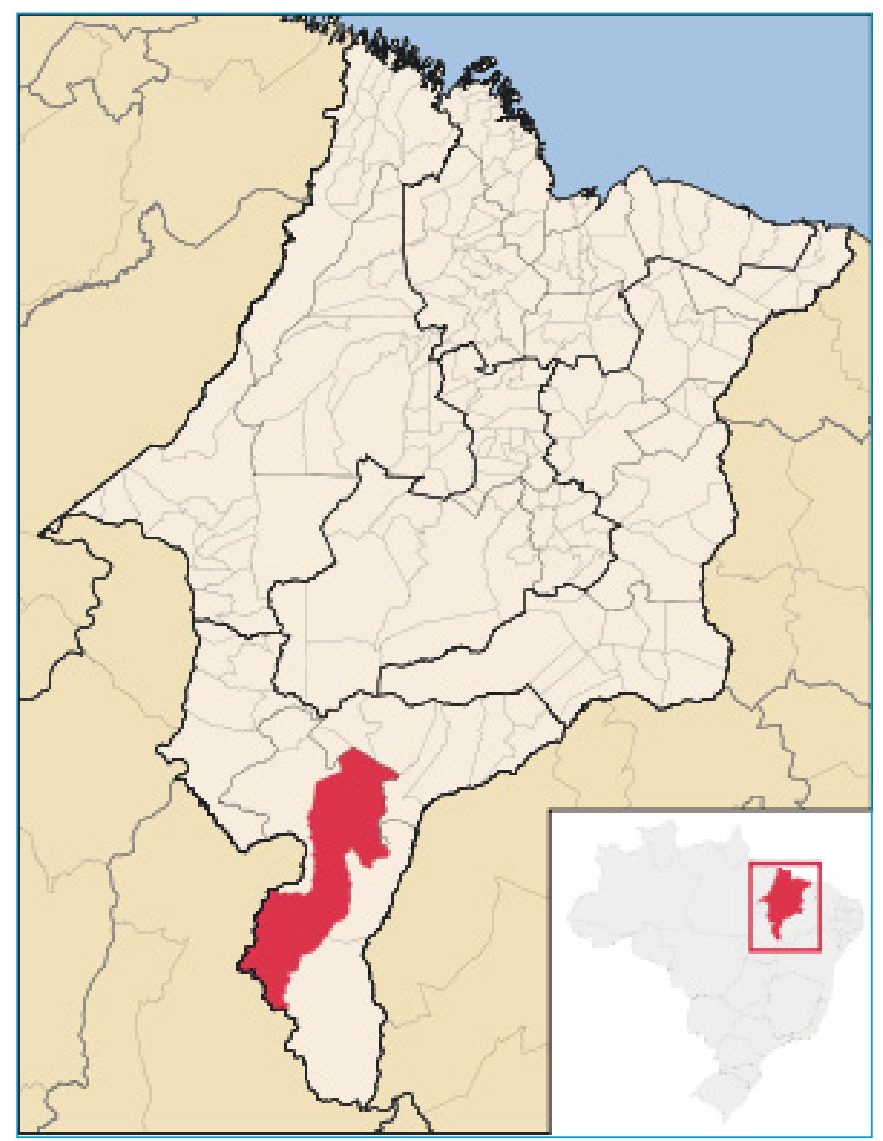

Figura 1 - Localização geográfica do município de Balsas (MA ABREU, 2006). de campo como: tipo de amostragem, localização dos pontos de amostragem, data e hora de coleta e condições meteorológicas nas últimas 24 horas antes da coleta. A temperatura e o $\mathrm{pH}$ da água foram medidos no local de coleta, assim como a concentração de oxigênio dissolvido (OD), em que um oxímetro portátil - AT 155 — foi utilizado. As medidas de condutividade das amostras foram feitas utilizando-se um condutivímetro, modelo DDS-12DW, Microprocessor Conductivity Meter, da marca $\mathrm{ION}^{\mathrm{O}}$. Os dados de turbidez foram obtidos em um turbidímetro, Plus II da ALFAKIT ${ }^{\text {. }}$ A determinação da dureza total, da concentração de nitrito, dos nitratos e do fósforo total, bem como as análises microbiológicas para determinação de coliformes totais e termotolerantes foram executadas segundo os métodos descritos no Standard Methods for the Examination of Water and Wastewater (EATON et al., 1998).

A partir dos dados obtidos, foi realizada uma análise comparativa, correlacionando os resultados com os limites máximos estabelecidos para os corpos d'água de classe I, II, III e IV, pela resolução CONAMA $n^{\circ} 357 / 2005$ (CONAMA, 2005), entre outras normas, como as estabelecidas pela CETESB (2005).

O Îndice de Qualidade da Água de Bascarán (IQAB - RIZZI, 2001) foi calculado pela Equação 1:

$\mathrm{IQAb}=\mathrm{k} \sum_{\mathrm{i}=1}^{\mathrm{n}} \mathrm{C}_{\mathrm{i}} \mathrm{P}_{\mathrm{i}} / \sum_{\mathrm{i}=1}^{\mathrm{n}} \mathrm{P}_{\mathrm{i}}$

Onde:

Ci é o valor porcentual do parâmetro i;

Pi é o peso de cada parâmetro i; e

$\mathrm{k}$ é a constante de ajuste,

em que se atribuiu diferentes valores em termos dos seguintes aspectos visuais da água: clara e sem contaminação aparente $(\mathrm{k}=1)$; cor indefinida, espuma, baixa turbidez aparente ou natural $(\mathrm{k}=0,75)$; aparência de contaminação e forte odor $(\mathrm{k}=0,5)$; negra, com fermentação e forte odor $(k=0,25)$. Neste trabalho, o valor de $k$ utilizado foi de 0,75 , já que o aspecto visual da água em todos os pontos investigados apresentou-se com turbidez aparente e cor indefinida.

Os parâmetros investigados foram agrupados de modo que possibilitem a classificação qualitativa das águas do riacho entre uma das categorias: boa, aceitável, regular, ruim ou péssima, cujos limites estabelecidos são: $91 \leq \mathrm{IQAb} \leq 100,61 \leq \mathrm{IQAb}<91,31 \leq \mathrm{IQAb}<61,16 \leq \mathrm{IQAb}<31$ e $0 \leq \mathrm{IQAb}<16$, respectivamente (VON SPERLING, 2007).

\section{RESULTADOS E DISCUSSÃO}

Os dados referentes aos parâmetros físicos, químicos e biológicos obtidos das análises das amostras de água do riacho São Caetano, coletadas nos pontos P1, P2, P3 e P4, nos meses de março, abril e maio de 2015, estão apresentados na Tabela 1. 
Constatou-se que, nos quatro pontos investigados durante os três meses de estudo, os valores de temperatura variaram na faixa de 16,0 $21,0 \pm 0,1{ }^{\circ} \mathrm{C}$, indicando que o lançamento de efluentes no riacho não apresenta impacto relevante sobre a temperatura de suas águas.
Os resultados de turbidez mostram que em todos os casos os níveis de turbidez do riacho estão acima de 50 UNT e abaixo de 100 UNT, estando, portanto, de acordo com os limites estabelecidos por lei na resolução do CONAMA n 357/2005 (CONAMA, 2005), cujo padrão

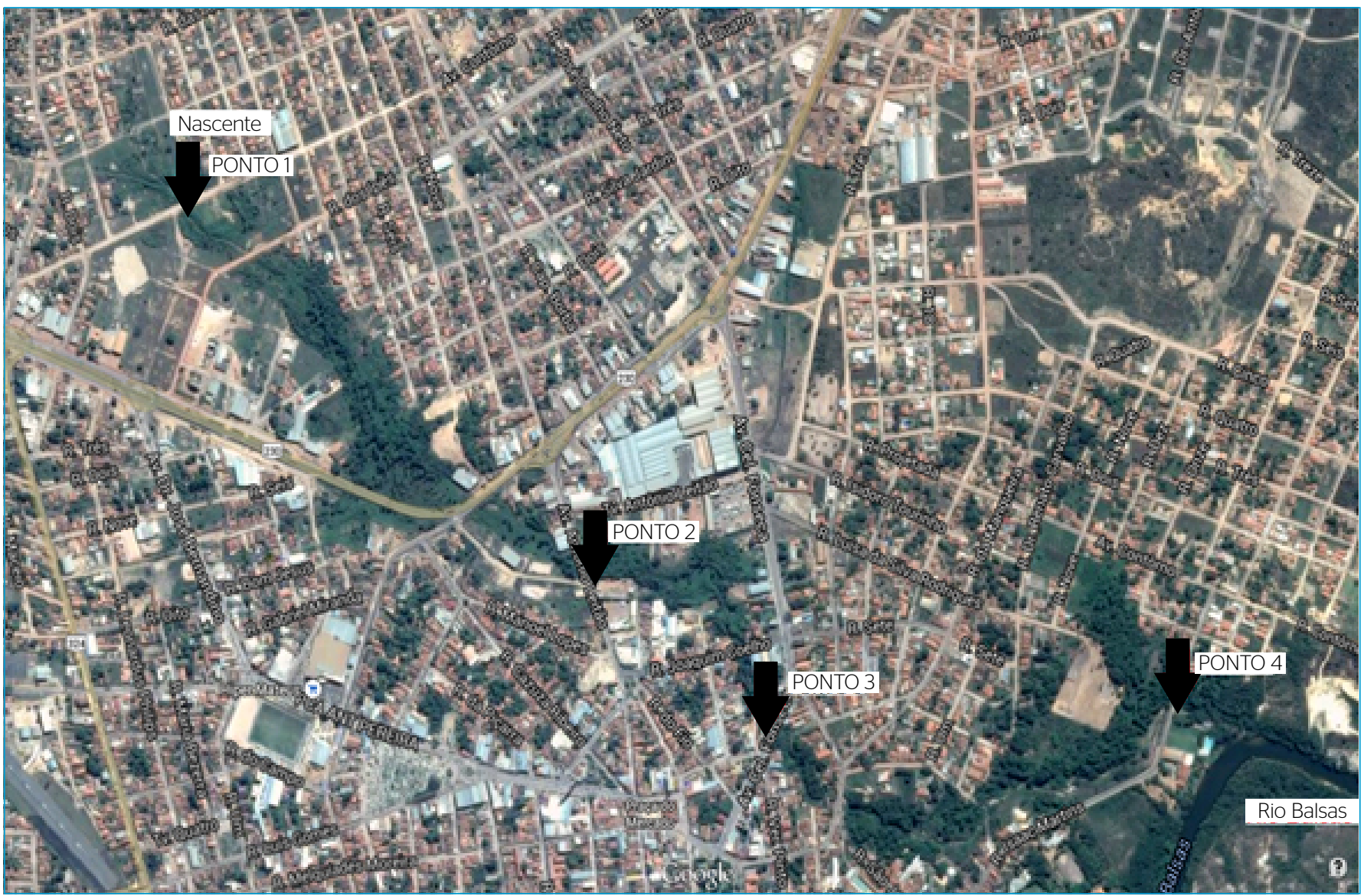

Figura 2 - Percurso do riacho São Caetano no perímetro urbano de Balsas e localização dos pontos de coleta (GOOGLE MAPS, 2015).

Tabela 1 - Valores dos parâmetros físicos, químicos e biológicos das amostras de água do riacho São Caetano coletadas em pontos determinados nos meses de março, abril e maio de 2015.

\begin{tabular}{|c|c|c|c|c|c|c|c|c|c|c|c|c|}
\hline \multirow{2}{*}{ Parâmetros } & \multicolumn{4}{|c|}{ Março } & \multicolumn{4}{|c|}{ Abril } & \multicolumn{4}{|c|}{ Maio } \\
\hline & P1 & P2 & P3 & P4 & P1 & P2 & P3 & P4 & P1 & P2 & P3 & P4 \\
\hline Temperatura $\left(^{\circ} \mathrm{C}\right)$ & 17,8 & 16,0 & 16,0 & 18,0 & 20,0 & 20,0 & 20,0 & 21,0 & 18,0 & 18,0 & 18,0 & 18,0 \\
\hline Turbidez (UNT) & \multicolumn{4}{|c|}{$>50$ turbidez $<100$} & \multicolumn{4}{|c|}{$>50$ turbidez $<100$} & \multicolumn{4}{|c|}{$>50$ turbidez $<100$} \\
\hline Condutividade $\left(\mu \mathrm{S} . \mathrm{cm}^{-1}\right)$ & 208 & 229 & 300 & 333 & 241 & 201 & 214 & 203 & 139 & 123 & 183 & 216 \\
\hline $\mathrm{OD}\left(\mathrm{mg} \cdot \mathrm{L}^{-1}\right)$ & 5,3 & 7,2 & 12,5 & 12,0 & 7,6 & 6,2 & 9,8 & 9,8 & 11,3 & 13,4 & 10,8 & 12,6 \\
\hline Nitrato (mg. L'1) $^{-1}$ & 2,20 & 0,00 & 2,00 & 1,00 & 2,00 & 0,00 & 1,50 & 2,40 & 2,20 & 0,20 & 0,70 & 2,00 \\
\hline Nitrito (mg. $\left.\mathrm{L}^{-1}\right)$ & 0,01 & 0,03 & 0,16 & 0,49 & 0,16 & 0,03 & 0,16 & 0,03 & 0,10 & 0,10 & 0,07 & 0,16 \\
\hline Fósforo total (mg. $\left.\mathrm{L}^{-1}\right)$ & 0,24 & 0,24 & 0,24 & 0,24 & 0,24 & 0,24 & 0,24 & 0,24 & 0,24 & 0,24 & 0,24 & 0,24 \\
\hline $\mathrm{pH}$ & 7,29 & 7,41 & 7,67 & 7,64 & 7,36 & 7,08 & 7,23 & 7,81 & 7,96 & 7,51 & 7,46 & 7,42 \\
\hline Dureza (mg $\left.\mathrm{CaCO}_{3} \mathrm{~L}^{-1}\right)$ & 148,2 & 105,6 & 135,0 & 163,0 & 42,2 & 77,6 & 115,6 & 147,6 & 34,2 & 50,2 & 67,6 & 82,2 \\
\hline $\mathrm{CT}\left(\mathrm{UFC} \cdot \mathrm{mL}^{-1}\right) \times 10^{3}$ & 2,9 & 40,0 & 11,0 & 1,9 & 1,6 & 1,4 & 2,5 & 1,1 & 5,3 & 2,2 & 8,1 & 3,8 \\
\hline CF $\left(\right.$ UFC.mL $\left.m L^{-1}\right) \times 10^{3}$ & 0,9 & 1,7 & 2,3 & 0,3 & 1,3 & 0,8 & 1,4 & 2,0 & 1,6 & 0,9 & 2,7 & 1,0 \\
\hline
\end{tabular}

OD: Oxigênio Dissolvido ; CT: Coliformes Totais; CF: Coliformes Fecais. 
é de até 100 UNT para corpos d'água de classe 2. Isso indica que a turbidez apresentada não interfere de forma significativa nos processos fotossintéticos das plantas aquáticas e das algas, nem na oxigenação do corpo d'água do riacho São Caetano.

Os valores de $\mathrm{pH}$ encontrados variaram na faixa de 7,23 a 7,96, de modo que em todos os casos os dados foram satisfatórios, já que o limite de $\mathrm{pH}$ para os sistemas aquáticos estabelecido pela resolução do CONAMA n ${ }^{\circ}$ 357/2005 (CONAMA, 2005) é na faixa de $\mathrm{pH}$ de 6,0 a 9,0 . Assim, em termos de potencial hidrogeniônico, as águas do riacho São Caetano, no período estudado, são caracterizadas como levemente básicas ou alcalinas ( $\mathrm{pH}>7,0)$, estando adequadas para a vida aquática.

Os valores de dureza total variaram na faixa de 34,2 a $163,0 \mathrm{mg}$ $\mathrm{CaCO}_{3} \cdot \mathrm{L}^{-1}$, de modo que no mês de março a água do riacho foi classificada como água dura, no mês de maio, como água moderada, e no mês de abril houve um aumento na dureza da água ao longo do curso do riacho (de P1 a P4), fato indicativo do aumento da incidência de material calcário, possivelmente proveniente de ações como assoreamento e erosão. Isso está de acordo com as atividades antrópicas observadas ao longo do riacho, especialmente nas proximidades dos pontos $\mathrm{P} 3 \mathrm{e} \mathrm{P} 4$, que foram os que apresentaram os maiores valores de dureza para cada mês. Contudo, apesar de esses dados não serem alarmantes, isso pode ser um indício de preocupações ao longo dos anos, se nenhuma providência for tomada.

Os valores de condutividade evidenciam a alta condutividade elétrica em todos os casos com variações entre 122,9 e 333,0 $\mu \mathrm{S} . \mathrm{cm}^{-1}$ (Figura 3), estando acima do limite estabelecido pela CETESB (2004), que é de $100 \mu \mathrm{S}$. $\mathrm{cm}^{-1}$, o que classifica o riacho São Caetano como ambiente impactado, já que valores altos de condutividade da água podem atribuir características corrosivas. Como os valores de $\mathrm{pH}$ e temperatura não apresentaram variações significativas, e a chuva acumulada nas últimas 48 horas foi de aproximadamente $0 \mathrm{~mm}$, sugere-se que os altos valores de condutividade

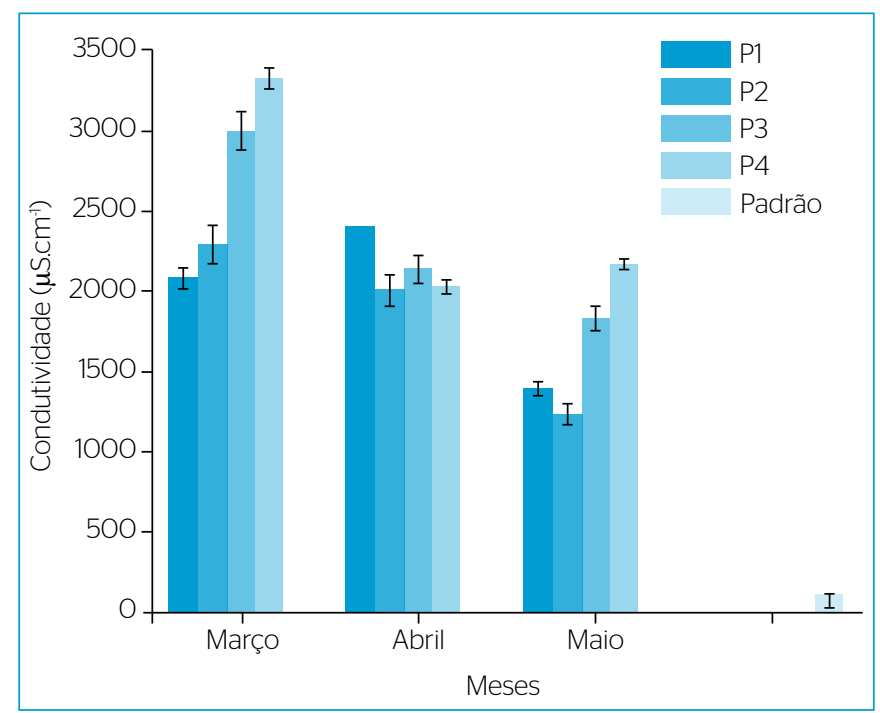

Figura 3 - Dados da condutividade das águas analisadas em P1, P2, P3 e P4, nos meses de março, abril e maio de 2015. estão associados, principalmente, à dureza da água, devido à presença

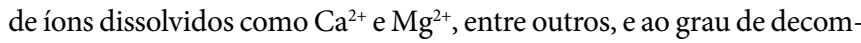
posição de material orgânico, gerando compostos iônicos dissolvidos.

Os dados referentes à determinação de nitrito revelam que a concentração varia na faixa de 0,01 a $0,49 \mathrm{mg} . \mathrm{L}^{-1}$, estando dentro do limite estabelecido pela resolução do CONAMA n 357/2005 (CONAMA, 2005), que é de $1,0 \mathrm{mg}$. $\mathrm{L}^{-1}$. Isso sugere a baixa incidência do processo de nitrificação e ainda que, com relação a esse parâmetro, as águas do riacho estão dentro dos padrões estabelecidos para corpos hídricos classe 2.

Os valores das concentrações de nitrato obtidos variaram na faixa de 0,00 a 2,40 mg. $\mathrm{L}^{-1}$, evidenciando a baixa concentração de nitrato nas águas do riacho no período estudado, estando, portanto, inferior ao limite recomendado pela resolução do CONAMA no 357/2005 (CONAMA, 2005) para corpos hídricos classe 2, que é de 10 mg.L-1.

$\mathrm{O}$ valor da concentração de fósforo total obtido foi de $0,24 \mathrm{mg} . \mathrm{L}^{-1}$ em todos os casos, o que coloca a água do riacho São Caetano na classificação 4 com base na resolução do CONAMA n 357/2005 (CONAMA, 2005). O alto índice de fósforo encontrado pode estar associado com $\mathrm{o}$ lançamento de esgotos domésticos com alto teor de detergentes fosfatados e matéria fecal, além da degradação de pesticidas orgânicos que contêm fosfatos em suas estruturas, fato este bastante pertinente por se tratar de uma região de intensas atividades agrícolas, cuja drenagem pluvial pode ser uma fonte potencial de fósforo para os corpos d'água. De fato, os dados encontrados para esse parâmetro mostram um índice preocupante, já que o fósforo possui elevada toxicidade em sua forma elementar, além de causar a eutrofização das águas.

Foi constatado em todos os casos que a concentração de OD está acima de 5,0 mg.L $\mathrm{L}^{-1}$, estando de acordo com os limites estabelecidos pela resolução do CONAMA no 357/2005 (CONAMA, 2005) para corpos d'água de classe 2. Porém, os pontos $\mathrm{P} 3$ e P4, no mês de março, e todos os pontos analisados no mês de maio apresentaram concentrações de OD acima de $10 \mathrm{mg} . \mathrm{L}^{-1}$, o que sugere o desenvolvimento, acima do normal, de algas nesses locais (ANA, 2009), possivelmente devido à eutrofização das águas, caracterizando uma situação de supersaturação ocasionada pelos altos níveis de nutrientes como fósforo, conforme discutido anteriormente. Isso acontece porque a grande disponibilidade de nutrientes favorece o crescimento excessivo de algas, cuja fotossíntese durante o dia eleva a concentração de OD na água. Mas como a fotossíntese não ocorre no período da noite, a concentração de OD diminui significativamente em função da respiração dos organismos aquáticos, podendo levar à morte de vários deles, inclusive dos peixes.

Foi verificado que todas as amostras de água analisadas possuem a presença de coliformes termotolerantes, cuja variação de concentração está na faixa de 300 a 2.700 UFC. $100 \mathrm{~mL}^{-1}$ de amostra (Figura 4).

Em geral, as águas coletadas no ponto P3, em março, apresentaram os maiores índices de coliformes fecais, com contaminação de 1.400 a 2.700 UFC.100 $\mathrm{mL}^{-1}$, o que se deve, possivelmente, aos lançamentos 
de esgotos domésticos nas proximidades do referido local investigado, conforme é mostrado na Figura 5. O ponto P1 apresentou valores de coliformes fecais na faixa de 900 a 1.600 UFC. $100 \mathrm{~mL}^{-1}$, entre os meses de março e maio, e, por se tratar de uma nascente, os valores podem ser considerados elevados. No entanto, a contaminação pode ser explicada pelo fato de o riacho São Caetano estar inserido no perímetro urbano. A média dos valores em P1 foi de aproximadamente 1.266 UFC.100 $\mathrm{mL}^{-1}$, o que classifica as águas desse ponto como de classe 3 , de acordo com as Resolução 357 do CONAMA. As águas desse ponto, portanto, estão aptas ao uso em recreações de contato secundário, porém inadequadas para a irrigação de hortaliças, de plantas frutíferas e de jardins, além de não serem aptas para uso na aquicultura e em atividades de pesca.

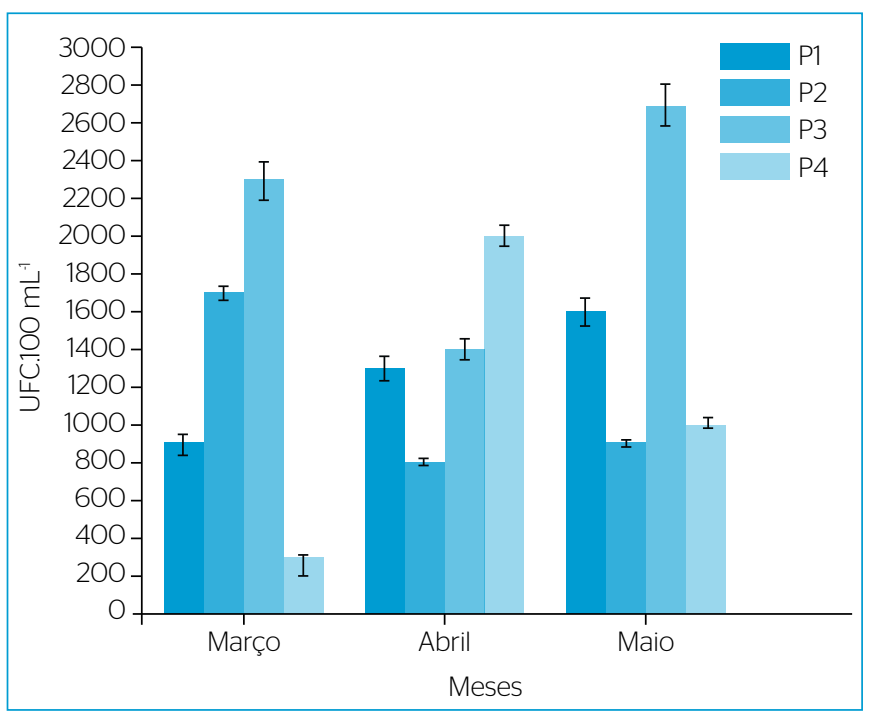

Figura 4 - Gráfico dos valores de coliformes totais encontrados nos pontos analisados nos meses de março, abril e maio de 2015.
Contudo, somente a água do ponto $\mathrm{P} 3$, coletada em maio, apresentou-se acima do limite de 2.500 UFC. $100 \mathrm{~mL}^{-1}$, passando a ser enquadrada na classe 4 , o que a limita a ser destinada somente para a navegação e para harmonia paisagística.

Portanto, a alta contaminação por coliformes fecais revela o alto índice de deposição diária de resíduo orgânico animal no solo e/ou o lançamento de esgotos domésticos sem tratamentos prévios, de modo que aumente o risco da aquisição de doenças patogênicas por parte da população que entra em contato com as águas contaminadas.

\section{Análise dos valores de IQAb}

Os valores do Índice de Qualidade de Bascarán (IQAb) obtidos com base nos parâmetros investigados neste estudo durante os meses de março, abril e maio, nos pontos P1, P2, P3 e P4, estão listados na Tabela 2 e apresentados na Figura 6.

De acordo com os dados, constata-se que as águas dos quatro pontos investigados são, qualitativamente, classificadas com qualidade regular. Entretanto, o ponto P3 demonstrou menor valor de IQAb, o que

Tabela 2 - Dados do Índice de Qualidade de Bascarán (IQAb) obtidos a partir dos parâmetros analisados da água coletada nos pontos P1, P2, P3 e P4 nos meses de março, abril e maio de 2015.

\begin{tabular}{l|c|c|c|c}
\multirow{2}{*}{ Pontos } & \multicolumn{4}{|c}{ Valor médio de IQA } \\
\cline { 2 - 5 } & Março & Abril & Maio & Média \\
\hline P1 & 52,94 & 52,06 & 47,65 & 50,88 \\
\hline P2 & 47,20 & 56,47 & 52,94 & 52,20 \\
\hline P3 & 44,12 & 48,75 & 48,09 & 46,99 \\
\hline P4 & 48,97 & 54,38 & 47,42 & 50,26 \\
\hline Média & 48,31 & 52,91 & 49,02 & - \\
\hline
\end{tabular}

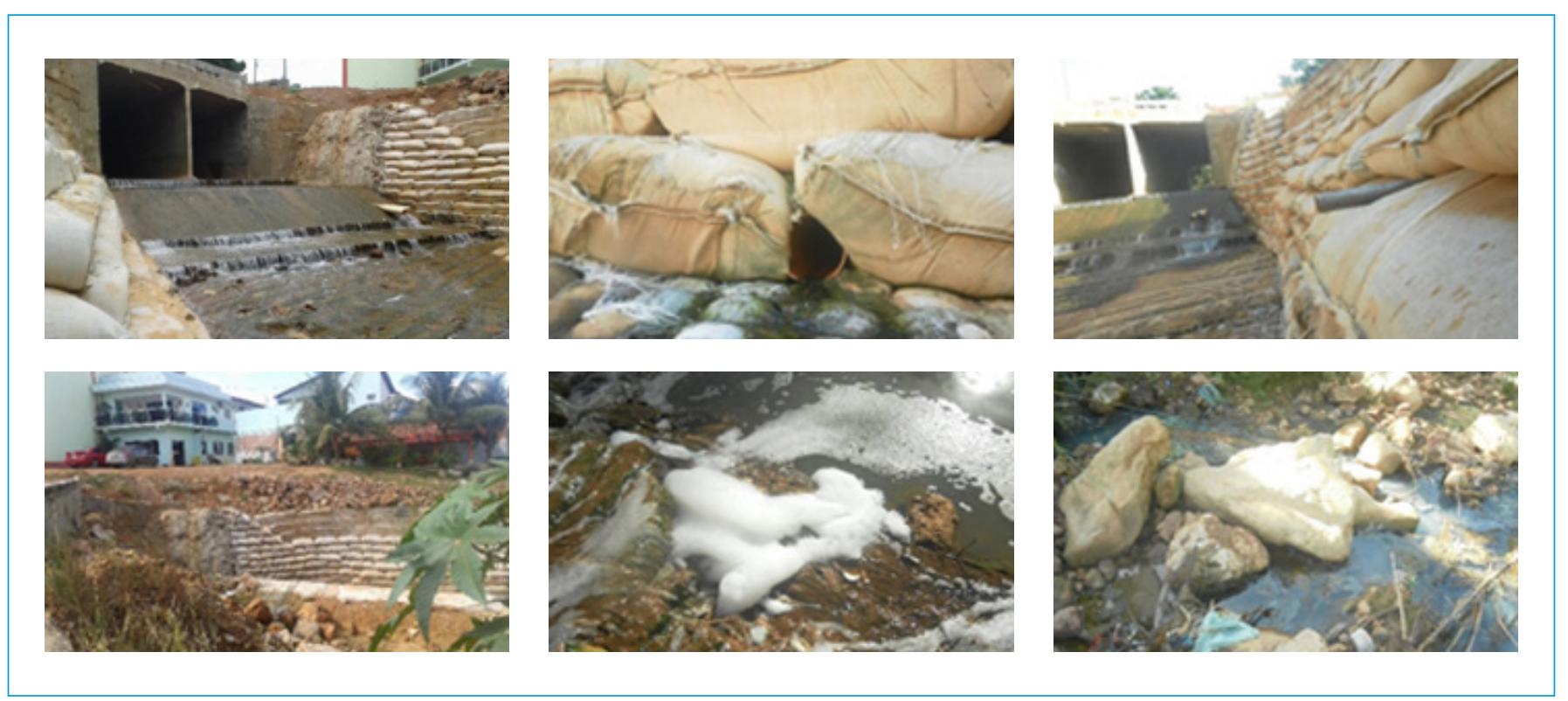

Figura 5 - Imagens de atividades antrópicas próximo ao P3. 
é coerente, uma vez que as observações feitas em campo e através das análises mostram que, de modo geral, os maiores impactos ambientais são observados nesse ponto. Os valores médios de IQAb determinados para as águas analisadas nos meses de março, abril e maio foram 48,31, 52,91 e 49,02, respectivamente, e estão apresentados na Tabela 2 e na Figura 7. Embora a qualidade tenha sido regular nos três meses de estudo, ela foi ligeiramente superior no mês de abril, o que pode estar associado à maior precipitação de média mensal de chuvas nesse período, em comparação aos meses de março e maio.

\section{Informações qualitativas referentes ao riacho São Caetano}

Com o crescimento populacional do centro de Balsas e a valorização dos bairros adjacentes, houve um rápido crescimento de bairros periféricos, levando ao aumento do perímetro urbano. Esse processo fez com que a cidade envolvesse as margens dos riachos do município, inclusive o riacho São Caetano, o qual se encontra em estado de degradação moderada e, se nada for feito, as atividades antrópicas podem comprometê-lo ainda mais.

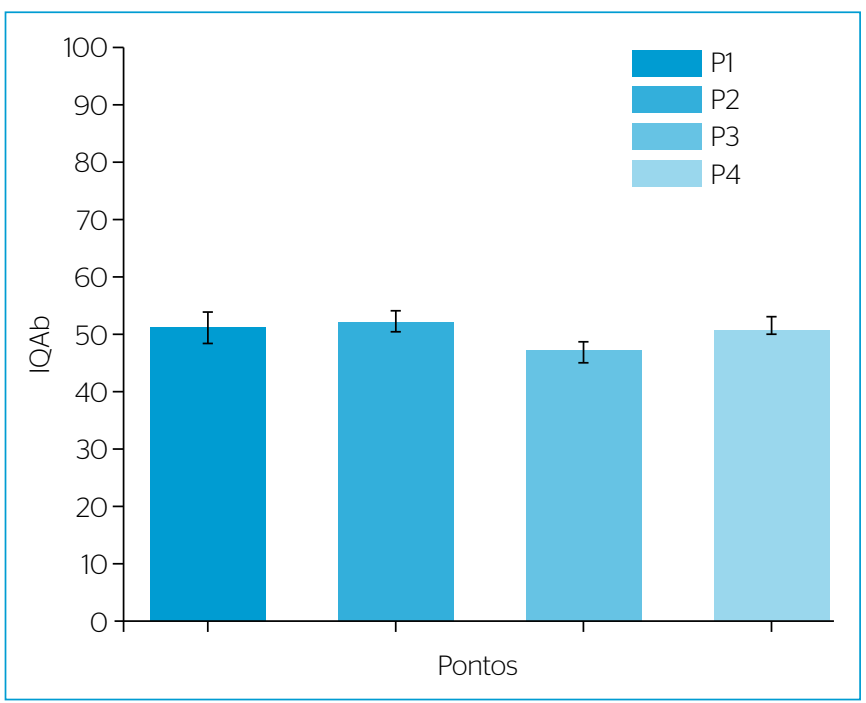

Figura 6 - Valores médios do Índice de Qualidade de Bascarán (IQAb) da água nos pontos P1, P2, P3 e P4, investigados ao longo do riacho São Caetano durante os meses de março, abril e maio de 2015.
As principais informações qualitativas referentes ao riacho São Caetano, registradas no mês de março de 2015, são listadas na Tabela 3 .

De acordo com as observações feitas, o lançamento de efluentes no riacho ocorre principalmente pelas casas situadas às margens do riacho, que posicionam os encanamentos voltados para dentro dele. Também foi constatado o depósito de lixo em vários pontos nos entornos do riacho, contribuindo para a diminuição de sua capacidade e para o aumento dos riscos de enchentes. Verificou-se ainda a presença de erosão e aterros e a ausência de vegetação ciliar nativa em muitos pontos, especialmente no P3. Portanto, existe a necessidade de medidas e ações que possam assegurar uma melhor qualidade da água do riacho São Caetano.

\section{CONCLUSÕES}

A água do riacho São Caetano, nos pontos analisados, está de acordo com os padrões estabelecidos para águas de classe 2 pela Resolução 357/2005 do CONAMA, nos seguintes parâmetros

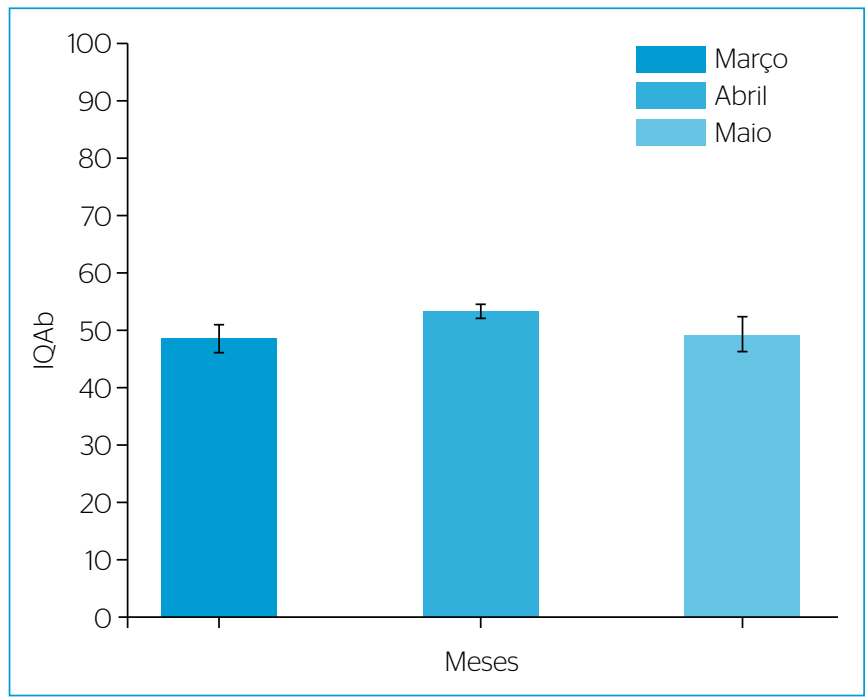

Figura 7 - Valores médios do Índice de Qualidade de Bascarán (IQAb) da água do riacho São Caetano, analisadas nos meses de março, abril e maio de 2015

Tabela 3 - Principais características observáveis referentes ao riacho São Caetano, registradas no mês de março de 2015 nos pontos P1, P2, P3 e P4.

\begin{tabular}{l|c|c|c|c} 
Características & P1 & P2 & P3 & P4 \\
Substrato & $\begin{array}{c}\text { Materiais plásticos; isopor; } \\
\text { lixo doméstico; etc. }\end{array}$ & $\begin{array}{c}\text { Esgotos; fezes de animais; } \\
\text { materiais plásticos; etc. }\end{array}$ & $\begin{array}{c}\text { Esgotos; materiais plásticos; } \\
\text { pneus; materiais de } \\
\text { construção; lixo doméstico. }\end{array}$ & $\begin{array}{c}\text { Materiais plásticos e } \\
\text { esgoto doméstico. }\end{array}$ \\
\hline Vegetação ribeirinha & Rasteira & Arbustiva & Ausente & Rasteira \\
\hline Impacto observado & $\begin{array}{c}\text { Atividades urbanas (resíduos } \\
\text { domésticos, ocupação das } \\
\text { margens, etc.) }\end{array}$ & $\begin{array}{c}\text { Atividades urbanas (resíduos } \\
\text { domésticos, ocupação das } \\
\text { margens, lava jatos, etc.) }\end{array}$ & $\begin{array}{c}\text { Atividades urbanas (resíduos } \\
\text { domésticos, ocupação das } \\
\text { margens, lava jatos, etc.) }\end{array}$ & $\begin{array}{c}\text { Atividades urbanas (resíduos } \\
\text { domésticos, ocupação das } \\
\text { margens, etc.) }\end{array}$ \\
\hline Erosão das margens & Pouca & Pouca & Acentuada & Moderada \\
\hline
\end{tabular}


físico-químicos: temperatura, turbidez, $\mathrm{pH}$, amônia, nitrito, nitrato e nitrogênio mineral. Os resultados de dureza total classificam as águas do riacho como dura a moderada ao longo do seu curso, enquanto os dados de condutividade e fósforo enquadram o riacho São Caetano como ambiente impactado. Os valores de coliformes fecais, em geral, estão acima do permitido pela referida resolução, caracterizando a água do manancial como imprópria para usos primário e secundário, sem tratamento prévio. Os valores de IQAb são indicativos de que as águas do riacho São Caetano possuem qualidade regular.

O riacho São Caetano vem sofrendo grandes impactos, principalmente por meio de atividades antrópicas, fazendo-se necessário seu monitoramento constante. Nesses termos, os resultados obtidos neste trabalho podem, eventualmente, corroborar na intervenção para a revitalização e manutenção da boa qualidade das águas do riacho São Caetano.

\section{REFERÊNCIAS}

ABREU, R.L. (2006) Maranhão Municip Balsas - Image:Maranhao MesoMicroMunicip.svg, own work. Licenciado sob CC BY 2.5, via Wikimedia Commons. Disponível em: <https://commons. wikimedia.org/wiki/File:Maranhao_Municip_Balsas.svg\#/media/ File:Maranhao_Municip_Balsas.svg>. Acesso em: O5 mar. 2015.

ANA - Agência Nacional de Águas. (2009) Indicadores de Qualidadeindice de qualidade das águas. Disponivel em <http://pnqa.ana.gov. br/IndicadoresQA/IndiceQA.aspx>. Acesso em: 25 maio 2015.

CETESB - Companhia de Tecnologia de Saneamento Ambiental. (2004) Relatório de qualidade das águas interiores do estado de São Paulo. Disponível em: < http://www.mpsp.mp.br/portal/page/ portal/cao_urbanismo_e_meio_ambiente/biblioteca_virtual/bv_ informativos_tecnicos/Relat\%C3\%B3rio\%2OAnual.pdf>. Acesso em: O3 fev. 2015

CETESB - Companhia de Tecnologia de Saneamento Ambiental. (2005) Decisão de Diretoria N0 195-2005-E - Valores Orientadores para Solos e Águas Subterrâneas no Estado de São Paulo. Disponível em: <http://www.ministeriodesalud.go.cr/gestores_en_salud/pozoAB-1089/ tabela_valores_2005.pdf>. Acesso em: 03 fev. 2015.

CETESB - Companhia de Tecnologia de Saneamento Ambiental. (2011) Guia nacional de coleta e preservação de amostras água, sedimento, comunidades aquáticas e efluentes líquidos. Disponível em: <http://www.clean.com.br/downloads/ Guia_Nacional_de_Coleta_e_Preservação_de_Amostras_pdf>. Acesso: 03 fev. 2015

CONAMA - Conselho Nacional do Meio Ambiente. Resolução no 357, de 17 de março de 2005. Dispõe sobre a classificação dos corpos de água e diretrizes ambientais para o seu enquadramento, bem como estabelece as condições e padrões de lançamento de efluentes, e dá outras providências. Diário Oficial da União, Brasília, DF.

EATON, A.D.; CLESCERI, L.S.; GREENBERG, A.E.; FRANSON, M.A.H. (1998) Standard methods for the examination of water and wastewater. 20 ed. Washington (DC): American Public Health Association, $1220 \mathrm{p}$

GOOGLE MAPS. (2015) Disponível em: <https://www.google.com. br/maps/@-7.5217576,-46.0458305,3011m/data=!3m1!1e3>. Acesso em: 05 fev. 2015

IBGE - INSTITUTO BRASILEIRO DE GEOGRAFIA E ESTATISTTICA (2010) Balsas/MA - informações completas. Disponível em: <http:// www.cidades.ibge.gov.br/xtras/perfil.php?lang=\&codmun=210140\& search=maranhaolbalsas>. Acesso em: 20 maio 2015.

OLIVEIRA, C.B. (2014) Poluição do Riacho São Caetano no perímetro urbano de Balsas-MA. 40 p. Monografia (Graduação em Ciências - habilitação em Biologia): Programa Darcy Ribeiro, Universidade Estadual do Maranhão, Balsas.

RIZZI, N.E. (2001) Índices de qualidade de água. Sanare - Revista Técnica Sanepar, v. 15, n. 15, p. 11-20

VON SPERLING, M. (2007) Estudos e modelagem da qualidade da água de rios. Princípios do tratamento biológico de águas residuárias. 3 ed. Belo Horizonte: Departamento de Engenharia Sanitária e Ambiental; Universidade Federal de Minas Gerais, v. 7, $588 \mathrm{p}$. 
DOI: 10.1590/S1413-41522017022000000040

\section{Errata}

No artigo "Avaliação da qualidade da água do riacho São Caetano, de Balsas (MA), com base emparâmetros físicos, químicos e microbiológicos", com número de DOI: 10.1590/S1413-41522017154657, publicado no periódico Revista Engenharia Sanitária e Ambiental, 22(3):523-529, na página 523:

Onde se lia:

Kalil Chaves Lima ${ }^{3}$

Leia-se:

Kalyl Chaves Lima ${ }^{3}$ 